\title{
Research Paper: Improvement of Subjective Well- Being in Students With Physical Disability: Mental Rehabilitation Based on Teaching Emotion Regulation Skills
}

Dana Mohammad Aminzadeh ${ }^{1,2}$, Yousef Asmari ${ }^{3}$, Sara Karimi ${ }^{1}$, Farideh Hosiensabet ${ }^{3}$, Mehdi Sharifi ${ }^{4}$

1. Department of Counseling, Faculty of Psychology \& Education, Allameh Tabataba'i University, Tehran, Iran. 2. Student Research Committee, University of Social Welfare and Rehabilitation Sciences, Tehran, Iran.

3. Department of Psychology, Faculty of Psychology \& Education, Allameh Tabataba'i University, Tehran, Iran.

4. Department of Counseling, University of Social Welfare and Rehabilitation Sciences, Tehran, Iran.

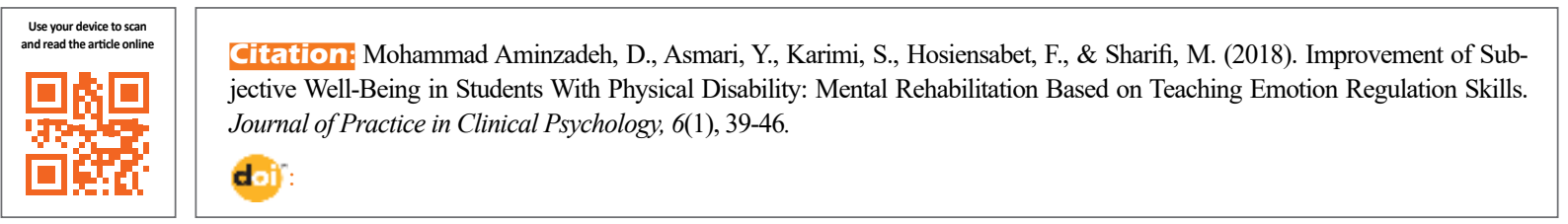

Article info:

Received: 14 Jun. 2017

Accepted: 12 Sep. 2017
Keywords:

Emotion regulation, Wellbeing, Students, Physical disability

\section{ABSTRACT}

Objective: Disability can affect people's quality of life and lead to lower mental health in life. The aim of this study was to evaluate the effectiveness of teaching emotion regulation skills as a way to increase subjective well-being in students with a physical disability.

Methods: This study employed a quasi-experimental design, with pretest-posttest, and control group. The study population comprised high school male students $(n=26)$ with a physical disability who were studying in the Soroush school, Tehran, a special school for students with a physical disability. Students were selected by Purposive sampling method and were assigned randomly to experimental and control groups $(n=13$, each group). The experimental group received eight sessions (twice a week) of emotion regulation skills, while the control group followed their daily routine. Keyes and Magyar-Moe Mental Health Continuum-Long Form (MHC-LF) were compared before and after the intervention between experimental and control groups.

Results: The findings of this study demonstrated that training of emotion regulation skills has a significant effect in the experimental group on increasing the subjective well-being of students with a physical disability $(\mathrm{P}<0.05)$ in comparison to control group. Data analysis was done using statistical software SPSS (version 23). MANCOVA test was performed to examine differences between the two groups

Conclusion: The training of emotion regulation skills could be an effective tool in improving the subjective well-being of students with a physical disability in the experimental group. The group training needs to be adopted by medical practitioners on a cohort for validating its effectiveness on a larger population.

\footnotetext{
* Corresponding Author:

Mehdi Sharifi, PhD Student

Address: Department of Counseling, University of Social Welfare and Rehabilitation Sciences, Tehran, Iran.

Tel: +98 (914) 6363076
}

E-mail: m_sharifi90@yahoo.com 


\section{Introduction}

ccording to WHO, disability is amongst 1 the International Classification of Functioning, Disability, and Health. It is also an umbrella term covering impairments, limitations, and participation restrictions (Lucas-Carrasco et al., 2011) and causes body malfunctions (Aurora, 2014) depriving the participation of a person in social and personal life (Salehi, Tavakol, Shabani, \& Ziaei, 2015). One of these disabilities is a physical disability, defined as damage which limits significant activities of a person's life (Brown \& Turner, 2012). Physical disability, part of a wide range of disabilities, include people who have been defeated in using one of the organs or parts of the body for at least six months (Bahrampour, Ghamari, \& Amiri Majd, 2014).

A physical disability is among such disabilities which restricts the disabled person (Brown \& Turner, 2012). According to WHO statistics, nearly $10,000,000$ of the world population are physically disabled, two-thirds of whom live in the developing countries (Bahrampour et al., 2014). Studies have shown that the students get affected emotionally and mentally because of physical disability. These studies indicate that any disability weakens one's self-esteem (Nosek, Hughes, Swedlund, Taylor, \& Swank, 2003) and is the cause of mental anxiety disorder and depression (Salehi et al., 2015). Thus, due physical disability and problems in the natural growth, these students are more vulnerable to emotioninduced issues and unable to control emotional responses (Rodríguez-Fernández et al., 2016).

There are various definitions of emotional regulation, some theories agree in that emotional control includes skills related to emotional awareness and evaluation, emotional regulation and adaptive use of emotions (Berking, Wirtz, Svaldi, \& Hofmann, 2014; Susa et al., 2014). According to Gross' emotion regulation process model, emotion regulation entails all conscious and unconscious strategies which are employed to decrease control and increase emotional, behavioral and cognitive components of an emotional response referring to the abilities to understand emotions, adjust experience, and express emotions (Kingston, Chadwick, Meron, \& Skinner, 2007). In other words, emotional regulation is the control of emotions depending on the present situations (Koole, 2009), which means what emotions to feel, when and how to express them (Campos, Walle, Dahl, \& Main, 2011; Joormann, 2010).

The aim of emotional regulation is to regulate people's emotions with the employment of effective strategies (Hal- perin, 2013). Being able to regulate emotions exerts a big influence on one's well-being (Cheung, Gardner, \& Anderson, 2015) and leads to appropriate mental health, interpersonal relationships, and desirable educational performance (Gross \& John, 2003). Furthermore, difficulties in emotional regulation can cause problems such as mental disorder, depression, and anxiety (Shepherd \& Wild, 2014).

Earlier studies have proved the effectiveness of teaching emotion regulation in the reduction of depression symptoms, anxiety, and stress (Gratz \& Gunderson, 2006). In a study by Gratz and Gunderson on women suffering from borderline personality disorder, it was demonstrated that intervention based on teaching emotion regulation has a marked effect on the reduction of emotional control disorder, experiential avoidance, self-harm, depression, anxiety, and stress (Gratz \& Gunderson, 2006). Berking et al. (2014) also found that about predicting the symptoms of depression based on the skill of emotion regulation, such an ability can be effective in finding the symptoms (Berking et al., 2014). Additionally, in another study by Mazaheri et al. (2014). it was reported that emotional regulation intervention was effective in a decrease of the severity of emotional symptoms (depression, anxiety, stress) and an increase in the patients quality of life with psychosomatic disorders (Mazaheri, Mohammadi, Daghaghzadeh, \& Afshar, 2014).

Emotions have an important role on one's health and thriving social life (Tortella-Feliu, Balle, \& Sesé, 2010) and their impact on all emotional and mental disorders (Tull \& Aldao, 2015) like depression, anxiety and interpersonal sensitivity (Reindl, Gniewosz, \& Reinders, 2016). Further, the emotions have a critical role of mental well-being on one's success, health, and reduction of psychological problems and teaching how to regulate emotions can be beneficial in reducing depression symptoms, increasing one's abilities and capabilities to enjoy life and the betterment of mental health. Therefore, the aim of the present study is to investigate the effect of mental rehabilitation by teaching emotion regulation skills on increasing the subjective well-being of students with a physical disability.

\section{Methods}

In the current study, a semi-experimental design with pre-test and post-test and control group was used for assessing the effectiveness of an independent variable on a dependent variable. The statistical population of this research included male students $(\mathrm{n}=26)$ with physical disability who were studying in the Tehran's high school (2016 academic year). The study population was chosen 
by purposive sampling method and were assigned randomly into experimental and control groups $(n=13$, each group). For each student a number was assigned, and the numbers were placed inside the box. Each number that came out of the box was placed one in the control group and one in the experimental group, respectively. Based on the scientific resources, the appropriate count for Formation group therapy sessions between 6 to 14 or 8 to 15 members was ideal (Corey, Corey, \& Corey, 2013).

The criteria for entering the research included: 1. Students with a physical disability; 2. Have normal IQ, the range of 90-110, (based on the files of counseling in school); 3. No history of psychiatric hospitalization (based on the advice of cases); 4. Willingness to participate in the study (via an interview in which they were marked); and 5. No concomitant treatment and the only criterion for leaving the study was the reluctance to continue. After forming the experimental and control groups, the experimental group was taught the emotional regulation skills for eight sessions of 90 minutes each for over a period of 45 days (twice a week). According to research ethics, after psychological intervention and the implementation of the post-test, researcher held one session of training emotion regulation skills for the control group.

To conduct this research, after receiving the necessary permissions from the research unit of Allameh Tabataba'i University, we referred to the Ministry of Education in Tehran. Regarding the 22 regions in Tehran, with purposive sampling method regions of two, four, sixteen that have schools with physical disabilities in these regions were selected as research regions. In the next step among the three regions present, the physical disability school that located in region 4 (Sroush school), according to the opinion of the researcher that have sufficient sample to participate in the research, was selected as an example. By referring to the school, according to the number of high school students, Mental Health Continuum-Long Form (MHC-LF) Inventory was performed for all students. In the next step, among all students who were implemented Mental Health Continuum-Long Form $(n=67)$ and whose score of MHC-LF Inventory was Lower than the rest $(n=26)$, as members samples were selected and randomly divided into experimental and control groups. The emotional regulation protocol was implemented for the experimental group, while the control group did not receive any training during this period and after completion of training sessions, Post-test was performed for the control and experimental groups. Finally, in a separate session, the emotional regulation skills for the control group were also explained.
Mental Health Continuum-Long Form (MHC-LF) is provided to measure growth and development of Mental health. This questionnaire is a comprehensive selfassessment report on subjective well-being that includes three general domains: Psychological, emotional, and social well-being. This questionnaire was designed by Keyes and Magyar-Moe which has 45 questions. The internal validity of emotional well-being was 0.91 and 0.78 in positive and negative sections, respectively. The subscales of psychological and social well-being had the average internal validity ranging from 0.40 to 0.70 , and the total validity of the subscales above was 0.80 and higher. The results of confirmatory factor Analysis has confirmed the three-factor structure of this scale (Golestani-bakht, 2007). Also, in a study by Dost it was reported that the coefficient of retrieval reliability of subjective well-being questionnaire was 0.86 . In this study, Cronbach's alpha coefficient of the questionnaire for overall subjective well-being was 0.73 , and Cronbach's alpha for each subscale of emotional, psychological and social well-being, respectively was obtained $0.78,0.72,0.74$.

Interventional method (i.e. training emotion regulation skills) was used. The treatment group was trained for eight sessions (every week, two sessions of sixty-minutes) while the control group did not receive any training. A summary of the training sessions is as follows:

The first session included re-testing, conceptualization, and the necessity of teaching emotion regulation. Second session included teaching the students about the awareness of positive emotions and their kinds (happiness, interest, and love) along with how to pay attention to positive emotions and the necessity of using them with examples like imagination, homework of writing about such emotions and filling in the questionnaires. Third session included reviewing the previous sessions and teaching them about the awareness of negative emotions and their kinds (anxiety, sadness, anger, and hatred) and about how to pay attention to these emotions and the necessity of using them with examples like imagination, homework of writing about such emotions and filling in the questionnaire.

Fourth session included reviewing the previous sessions, teaching them about the acceptance of positive emotions and how to accept emotions without judging the intensity or number of positive and negative emotions and the positive or negative results of using them, homework about asking other people's opinions like a spouse or a close friend about the intensity of their emotions and filling in the questionnaire. Fifth session included teaching the same material of the previous sessions for nega- 
tive emotions and assigning similar homework. Sixth session included reviewing the last session, teaching re-evaluation and the expression of positive emotions, teaching how to imagine positive emotions, cognitive inhibition and to express these emotions appropriately. Seventh session included reviewing previous sessions, teaching re-evaluation and the expression of negative emotions, teaching how to imagine negative emotions, appropriate expression of them and avoiding the inappropriate expression of negative emotions. Eighth session included concluding and conducting the post-test.

\section{Results}

The average range of representative sample was 15.8 $(n=26)$ with the standard variation (SD) of 3.47. Multivariate analysis of covariance has been used to investigate the effect of the intervention, in which the following defaults should be checked first: the equality of variance, the homogeneity of regression slopes and normal distribution. To investigate the homogeneity of variance of the two groups in post-testing level, Levene's test of variance homogeneity has been used. Levene's test was not significant for any of the investigated variables [Post-tests, the overall index of mental well-being $(\mathrm{P}=0.2>0.05)$ emotional well-being component $(\mathrm{P}=0.1>0.05)$ social well-being $(\mathrm{P}=0.9>0.05)$ psychological well-being $(\mathrm{P}=0.45>0.05)]$. Therefore, in the post-test the homogeneity of variances was confirmed. The interaction between pre-test and mental well-being and its subscales helped to the investigation of the test of homogeneity of regression coefficients and the independent variables in the post-test. The interaction between these pre-tests was not significant and indicated the homogeneity of regression coefficients. Thus, the assumption of the homogeneity of regression coefficients was confirmed. Given all the results, the multivariate analysis of covariance was elaborated. The descriptive test results of the experimental and control groups (Including mean and SD) are presented in Table 1.

In Table 2, the multivariate statistics, i.e., Wilks' Lambda is $95 \%(\alpha=0.05)$ significant $[\eta \dot{2}=0.95, \mathrm{P}<0.05$, $\left.\mathrm{F}_{(3,21)}=165.8\right]$ on the confidence level; therefore, the null hypothesis is rejected. Thus, it is concluded that the multivariate analysis of covariance is significant; in other words, results show that the treatment method of emotion regulation was influential on the linear combination of the dependent variable (post-test and its subscales) and the difference between the mean of the two dependent variables is reliable.

As it is shown in Table 3, after adjusting the scores of pre-test, the average scores of the post-test are as it follows: emotional well-being $\left(\mathrm{F}_{(1,23)}=494.7, \mathrm{P} \leq 0.001\right)$, emotional components $\left(\mathrm{F}_{(1,23)}=316.6, \mathrm{P} \leq 0.001\right)$ psychological components $\left(\mathrm{F}_{(1,23)}=490.6, \mathrm{P} \leq 0.001\right)$ and social components $\left(\mathrm{F}_{(1,23)}=268.6, \mathrm{P} \leq 0.001\right)$ of the two groups (control and treatment) are different. In other words, one can infer with $99 \%$ certainty that teaching emotion regulation to physically disabled students is very efficient

\section{Discussion}

The aim of this study was the mental rehabilitation of students with a physical disability based on teaching emotion regulation skills in groups to increase their subjective well-being. After using the intervention method of teaching emotion regulation during eight sessions, findings indicated an increase in the scores of these students' subjective well-being in the posttest of the treatment group.

Table 1. Descriptive statistics of mental health subscales (mean and standard deviation)

\begin{tabular}{|c|c|c|c|c|c|}
\hline \multirow{2}{*}{ Dependent Variable } & \multirow{2}{*}{ Group } & \multicolumn{2}{|c|}{ Pretest } & \multicolumn{2}{|c|}{ Posttest } \\
\hline & & $\mathbf{M}$ & SD & $\mathbf{M}$ & SD \\
\hline \multirow{2}{*}{ Emotional well-being } & Control & 23.4 & 5.35 & 22.7 & 4.7 \\
\hline & Experiment & 23.3 & 5.07 & 30.8 & 3.6 \\
\hline \multirow{2}{*}{ Psychological Well-Being } & Control & 35.8 & 7.2 & 35.3 & 6.3 \\
\hline & Experiment & 34.4 & 6.1 & 41.4 & 5.2 \\
\hline \multirow{2}{*}{ Social Well-Being } & Control & 30.5 & 5.1 & 29.4 & 4.4 \\
\hline & Experiment & 30.1 & 4.8 & 38.6 & 5.4 \\
\hline \multirow{2}{*}{ Overall subjective well-being } & Control & 88.4 & 16.06 & 87.2 & 14.6 \\
\hline & Experiment & 87.2 & 14.60 & 95.1 & 11.42 \\
\hline
\end{tabular}


Table 2. Information credit index of Multivariate analysis covariance of subjective well-being

\begin{tabular}{|c|c|c|c|c|c|c|c|}
\hline & Effect & Value & $f$ & Hypothesis df & Error df & $\mathbf{P}$ & Eta \\
\hline \multirow{4}{*}{ Intercept } & Pillai's Trace & 0.68 & 15.134 & 2.000 & 21 & 0.001 & 0.678 \\
\hline & Wilks' Lambda & 0.32 & 15.134 & 2.000 & 21 & 0.001 & 0.678 \\
\hline & Hotelling's Trace & 2.2 & 15.134 & 2.000 & 21 & 0.001 & 0.678 \\
\hline & Roy's Largest Root & 2.2 & 15.134 & 2.000 & 21 & 0.001 & 0.678 \\
\hline \multirow{4}{*}{ Gens } & Pillai's Trace & 0.96 & 165.8 & 2.000 & 21 & 0.001 & 0.95 \\
\hline & Wilks' Lambda & 0.04 & 165.8 & 2.000 & 21 & 0.001 & 0.95 \\
\hline & Hotelling's Trace & 23.3 & 165.8 & 2.000 & 21 & 0.001 & 0.95 \\
\hline & Roy's Largest Root & 23.3 & 165.8 & 2.000 & 21 & 0.001 & 0.95 \\
\hline
\end{tabular}

Table 3. Results of multivariate analysis of variance to compare the subjective well-being scores and its components in the experimental and control groups

\begin{tabular}{|c|c|c|c|c|c|c|c|}
\hline Dependent Variable & Source & S.S & df & M.S & $\mathbf{F}$ & Sig. & Eta \\
\hline \multirow{3}{*}{ Emotional well-being } & Group & 4487.9 & 1 & 4487.9 & \multirow{3}{*}{316.6} & \multirow{3}{*}{0.001} & \multirow{3}{*}{0.93} \\
\hline & & & & & & & \\
\hline & Error & 325.9 & 23 & 14.1 & & & \\
\hline \multirow{3}{*}{ Psychological well-Being } & Group & 9156.1 & 1 & 9156.1 & \multirow{3}{*}{490.6} & \multirow{3}{*}{0.001} & \multirow{3}{*}{0.95} \\
\hline & & & & & & & \\
\hline & Error & 429.2 & 23 & 18.66 & & & \\
\hline \multirow{3}{*}{ Social well-Being } & Group & 6378.9 & 1 & 6378.9 & \multirow{3}{*}{268.6} & \multirow{3}{*}{0.001} & \multirow{3}{*}{0.92} \\
\hline & & & & & & & \\
\hline & Error & 546.1 & 23 & 23.7 & & & \\
\hline \multirow{3}{*}{ Overall subjective well-being } & Group & 58829.6 & 1 & 58829.6 & \multirow{3}{*}{494.7} & \multirow{3}{*}{0.001} & \multirow{3}{*}{0.95} \\
\hline & & & & & & & \\
\hline & Error & 2734.8 & 23 & 118.9 & & & \\
\hline
\end{tabular}

Considering the neutralization of the effect of the score of subjective well-being in the pretest, it can be asserted that this huge difference is because of employing the independent variable. In other words, since only the treatment group was taught to regulate their emotions an increase in the scores of mental well-being of the treatment group was observed in comparison to the control group. These findings can be confirmed on prior findings based on the relationship of Re-evaluation as an emotion regulation strategy on well-being and mental health (Gross, 2002), emotion regulation strategies relationship with psychological distress (Garnefski \& Kraaij, 2006), and the critical role of emotion regulation in a favourable adjustment (Yoo, Matsumoto, \& LeRoux, 2006). According to these findings, it can be inferred that disabilities can cause severe mental and social problems due to their long-lasting effects on one's lifetime.
Disabled people differentiate themselves from others, are more vulnerable and mostly feel unpleasant about themselves. Therefore, these students are less able to handle their emotional responses, which make them have a low level of mental well-being. These students may not be aware of their positive and negative emotions and may face difficulties when they want to use these emotions in different situations. The reason behind this challenge is that they underestimate themselves in social situations which bring them anxiety, despair, and restlessness. Contrastively, emotion regulation is one of the methods with which they can create balance in their emotional experiences, reduce negative feelings, and increase positive feelings and compatibility.

Teaching emotion regulation to disabled people assists them to become aware of their negative emotions and the negative effects thereof on themselves (Susa et al., 
2014). By re-evaluating these emotions in different situations, they attempt to create a healthy emotional lifestyle and reduce their mental and physical problems and thus achieving emotional balance (Bardeen \& Fergus, 2014; Isasi, Ostrovsky, \& Wills, 2013). Besides, defects and disorders in regulating emotions are correlated with the vulnerability to suffer from depression (Oshri, Sutton, Clay-Warner, \& Miller, 2015) which causes many mental harms (Rutherford, Wallace, Laurent, \& Mayes, 2015) and can be the beginning of many more personal problems and the anxiety of well-being (Gross \& Thompson, 2007). Apparently, teaching emotion regulation can help these people to use their emotions appropriately and in return to use these trainings to encounter social hardships and improve their social relationships, psychological health, and evaluate their lives to be desirable and satisfactory, in which they can keep a balance between positive and negative emotions.

In conclusion, since emotions play an essential role in one's life, emotion regulation is a treatment to keep a balance between these emotions, self-esteem and positive interpersonal relationships and can help one to handle stressful situations more efficiently, and thus to be more active socially. Teaching physically disabled students to be aware of their negative and positive emotions and how to express them and how to control and modify negative emotions can guarantee their mental health.

The most important limitation of this research included purposive sampling and in result using a quasiexperimental model which reduced the extension of the findings. In the end, it is suggested that further studies on the effect of emotion regulation on other variables like despair and distress of disabled students should be performed. Moreover, further research on families whose children are disabled and assess the quality of their marital relationships are necessitated. According to psychopathology, the way these children are treated by their family members and how these family members behave in social situations strongly affect the amount of their vulnerability to stress.

\section{Acknowledgments}

The authors of this study genuinely appreciate the cooperation and kindness of all dear students and their principals in charge. It is hoped that with this research, educational and governmental institutions turn their attention more to disabled people. This study did not receive any financial support.

\section{Conflict of Interest}

The authors declared no conflicts of interest.

\section{References}

Aurora, U. (2014). Study for determining laterality in children with motor disabilities in adapted physical activities. Procedia-Social and Behavioral Sciences, 117, 646-652. doi: 10.1016/j. sbspro.2014.02.276

Bahrampour, O., Ghamari, M., \& Amiri Majd, M. (2014). The effectiveness of cognitive behavioral group therapy on selfesteem and psychological well-being of young people with physical-motor disabilities. Journal SIH, 2, 2345-2633.

Bardeen, J. R., \& Fergus, T. A. (2014). An examination of the incremental contribution of emotion regulation difficulties to health anxiety beyond specific emotion regulation strategies. Journal of Anxiety Disorders, 28(4), 394-401. doi: 10.1016/j. janxdis.2014.03.002

Berking, M., Wirtz, C. M., Svaldi, J., \& Hofmann, S. G. (2014). Emotion regulation predicts symptoms of depression over five years. Behaviour Research and Therapy, 57, 13-20. doi: 10.1016/j.brat.2014.03.003

Brown, R. L., \& Turner, R. J. (2012). Physical limitation and anger stress exposure and assessing the role of psychosocial resources. Society and Mental Health, 2(2), 69-84. doi: $10.1177 / 2156869312444441$

Campos, J. J., Walle, E. A., Dahl, A., \& Main, A. (2011). Reconceptualizing emotion regulation. Emotion Review, 3(1), 26-35. doi: $10.1177 / 1754073910380975$

Cheung, E. O., Gardner, W. L., \& Anderson, J. F. (2015). Emotionships examining people's emotion-regulation relationships and their consequences for well-being. Social Psychological and Personality Science, 6(4), 407-414. doi: $10.1177 / 1948550614564223$

Corey, M. S., Corey, G., \& Corey, C. (2013). Groups: Process and practice. Boston, Massachusetts: Cengage Learning.

Garnefski, N., \& Kraaij, V. (2006). Cognitive Emotion Regulation Questionnaire - development of a short 18-item version (CERQ-short). Personality and Individual Differences, 41(6), 1045-1053. doi: 10.1016/j.paid.2006.04.010

Golestani-Bakht, T. (2007). [Model of subjective well-being and happiness in Tehran (Persian)] [PhD Thesis]. Tehran: University of Alzahra.

Gratz, K. L., \& Gunderson, J. G. (2006). Preliminary data on an acceptance-based emotion regulation group intervention for deliberate self-harm among women with borderline personality disorder. Behavior Therapy, 37(1), 25-35. doi: 10.1016/j. beth.2005.03.002

Gross, J. J. (2002). Emotion regulation: Affective, cognitive, and social consequences. Psychophysiology, 39(3), 281-291. doi: $10.1017 / \mathrm{s} 0048577201393198$ 
Gross, J. J., \& John, O. P. (2003). Individual differences in two emotion regulation processes: Implications for affect, relationships, and well-being. Journal of Personality and Social Psychology, 85(2), 348-62. PMID: 12916575

Gross, J. J., \& Thompson, R. A. (2007). Emotion Regulation: Conceptual Foundations. In J. J. Gross (Ed.), Handbook of Emotion Regulation (pp. 3-24). New York: Guilford Press.

Halperin, E. (2013). Emotion, emotion regulation, and conflict resolution. Emotion Review, 6(1), 68-76. doi:10.1177/1754073913491844

Isasi, C. R., Ostrovsky, N. W., \& Wills, T. A. (2013). The association of emotion regulation with lifestyle behaviors in inner-city adolescents. Eating Behaviors, 14(4), 518-521. doi: 10.1016/j.eatbeh.2013.07.009

Joormann, J. (2010). Cognitive Inhibition and emotion regulation in depression. Current Directions in Psychological Science, 19(3), 161-166. doi: 10.1177/0963721410370293

Kingston, J., Chadwick, P., Meron, D., \& Skinner, T. C. (2007). A pilot randomized control trial investigating the effect of mindfulness practice on pain tolerance, psychological wellbeing, and physiological activity. Journal of Psychosomatic Research, 62(3), 297-300. doi: 10.1016/j.jpsychores.2006.10.007

Koole, S. L. (2009). The psychology of emotion regulation: An integrative review. Cognition $\mathcal{E}$ Emotion, 23(1), 4-41. doi: $10.1080 / 02699930802619031$

Lucas-Carrasco, R., Eser, E., Hao, Y., McPherson, K. M., Green, A., \& Kullmann, L. (2011). The Quality of Care and Support (QOCS) for people with disability scale: Development and psychometric properties. Research in Developmental Disabilities, 32(3), 1212-25. doi: 10.1016/j.ridd.2010.12.030

Mazaheri, M., Mohammadi, N., Daghaghzadeh, H., \& Afshar, H. (2014). [The effectiveness of emotion regulation intervention on emotional problems and quality of life among patients with functional gastrointestinal disorders (Persian)]. Govaresh, 19(2), 109-117.

Nosek, M. A., Hughes, R. B., Swedlund, N., Taylor, H. B., \& Swank, P. (2003). Self-esteem and women with disabilities. Social Science E Medicine, 56(8), 1737-1747. doi: 10.1016/s02779536(02)00169-7

Oshri, A., Sutton, T. E., Clay-Warner, J., \& Miller, J. D. (2015). Child maltreatment types and risk behaviors: Associations with attachment style and emotion regulation dimensions. Personality and Individual Differences, 73, 127-133. doi: 10.1016/j.paid.2014.09.015

Reindl, M., Gniewosz, B., \& Reinders, H. (2016). Socialization of emotion regulation strategies through friends. Journal of adolescence, 49, 146-157. doi: 10.1016/j.adolescence.2016.03.008

Rodríguez-Fernández, A., Ramos-Díaz, E., Fernández-Zabala, A., Goñi, E., Esnaola, I., \& Goñi, A. (2016). Contextual and psychological variables in a descriptive model of subjective well-being and school engagement. International Journal of Clinical and Health Psychology, 16(2), 166-174. doi: 10.1016/j. ijchp.2016.01.003

Rutherford, H. J. V., Wallace, N. S., Laurent, H. K., \& Mayes, L. C. (2015). Emotion regulation in parenthood. Developmental Review, 36, 1-14. doi: 10.1016/j.dr.2014.12.008
Salehi, M., Tavakol, H. K., Shabani, M., \& Ziaei, T. (2015). The relationship between Self-Esteem and sexual Self-Concept in people with Physical-Motor disabilities. Iranian Red Crescent Medical Journal, 17(1): e25359. doi: /10.5812/ircmj.25359

Shepherd, L., \& Wild, J. (2014). Emotion regulation, physiological arousal and PTSD symptoms in trauma-exposed individuals. Journal of Behavior Therapy and Experimental Psychiatry, 45(3), 360-367. doi: 10.1016/j.jbtep.2014.03.002

Susa, G., Mone, I., Salagean, D., Mihalca, L., Benga, O., \& Friedlmeier, W. (2014). The relation between maternal perception of toddler emotion regulation abilities and emotion regulation abilities displayed by children in a frustration inducing task. Procedia-Social and Behavioral Sciences, 128, 493497. doi: 10.1016/j.sbspro.2014.03.194

Tortella-Feliu, M., Balle, M., \& Sesé, A. (2010). Relationships between negative affectivity, emotion regulation, anxiety, and depressive symptoms in adolescents as examined through structural equation modeling. Journal of Anxiety Disorders, 24(7), 686-693. doi: 10.1016/j.janxdis.2010.04.012

Tull, M. T., \& Aldao, A. (2015). Editorial overview: New directions in the science of emotion regulation. Current Opinion in Psychology, 3, iv-x. doi: 10.1016/j.copsyc.2015.03.009

Yoo, S. H., Matsumoto, D., \& LeRoux, J. A. (2006). The influence of emotion recognition and emotion regulation on intercultural adjustment. International Journal of Intercultural Relations, 30(3), 345-363. doi: 10.1016/j.ijintrel.2005.08.006 
